\title{
“ALFABETIZAR” OU “LETRAR”? UMA DISCUSSÃO SOBRE AS PRÁTICAS PEDAGÓGICAS DE ALFABETIZAÇÃO NO ENSINO FUNDAMENTAL
}

Isabella Cristina Alves Pimenta, Flávia Lemos Rocha, Mariane Venturini da Silva, Nair Correia Salgado de Azevedo.

Universidade do Oeste Paulista - UNOESTE, Licenciatura em Pedagogia, Presidente Prudente, SP. E-mail: isabellapimenta@hotmail.com

\section{RESUMO}

Reconhecendo a importância da alfabetização para a melhora da qualidade da Educação uma das reflexões a ser realizada, segundo Soares (2003) parece ser o de reconhecer a importância e especificidade da "Alfabetização" nas séries iniciais, Nesse artigo, nos propomos a refletir sobre os métodos de alfabetização. Como objetivos específicos, nos propomos a: a) Entender do ponto de vista histórico como sugiram os conceitos de "Alfabetização" e "Letramento" e; b) Conceituar os termos "Alfabetização" e "Letramento". De caráter qualitativo e de cunho bibliográfico, essa pesquisa se utilizou da reflexão teórica crítica sobre o material obtido de estudos já realizados por autores renomados sobre o tema, como Soares (1989, 2003; 2004), Mortatti (2006), Ferreiro (1986; 1995). Concluímos que a educação já aderiu a diversos métodos de alfabetização, entretanto, não existe um método "certo" e "errado", e sim o uso adequado dele. Desta forma, deve-se fazer uso de diversos recursos para alfabetizar.

Palavras-chave: Educação. Alfabetização. Letramento. Método.

\section{"LITERACY" OR "LETTER"? A DISCUSSION ON THE PEDAGOGICAL PRACTICES OF LITERACY IN FUNDAMENTAL TEACHING}

\begin{abstract}
According to Soares (2003), recognizing the importance of literacy for the improvement of the quality of education, it seems to be the recognition of the importance and specificity of "Literacy" in the initial grades. In this article, we propose to reflect on the methods. As specific objectives, we propose to: a) Understand from the historical point of view how the concepts of "Literacy" and "Literacy" suggest; b) Define the terms "Literacy" and "Literacy". This research was based on a theoretical and critical reflection on the material obtained from studies already carried out by renowned authors on the subject, such as Soares (1989, 2003, 2004), Mortatti (2006), Ferreiro (1986; 1995). We conclude that education has already adhered to various methods of literacy, however, there is no "right" and "wrong" method, but proper use of it. In this way, it is necessary to make use of several resources for literacy.
\end{abstract}

Keywords: Education. Literacy. Literature. Method. 


\section{INTRODUÇÃO}

As preocupações com a qualidade da Educação pública no Brasil tem sido, ao longo de décadas, motivo de debates, reflexões e, especialmente, motivo também de preocupações por parte de gestores e governantes. Ao revelarem os resultados das avaliações oficiais ensino público, - Brasil nos mostra uma desafiadora realidade e junto com esse quadro preocupante (pois tais avaliações demonstram uma necessidade urgente de melhora na qualidade da Educação brasileira) existe a necessidade de ações concretas para que tal realidade se transforme.

Há que se saber, porém, que essas discussões não são recentes e existem tentativas de se aprimorar a qualidade da educação por meio do início do processo de escolarização, ou seja, por meio da alfabetização. Santos e Costa (2016), na mesma direção de Carneiro (2016), apontam para muitas tentativas de melhora da qualidade da Educação por meio de ações de políticas públicas, o Ciclo Básico e a "Escola Padrão" na década de 1980 em São Paulo, e mais recentemente, as escolas de tempo integral e os Programas de auxílio ao professor alfabetizador, como o "Ler e escrever", o "Letra e vida" e o "Pacto Nacional de Alfabetização na Idade Certa" - PNAIC.

Entretanto, nos propomos a refletir sobre os métodos de alfabetização, e analisamos os estudos realizados por Soares (2003), Mortatti (2006), Ferreiro (1986; 1995), entre outros, percebemos que no Brasil houve uma distorção entre os termos "alfabetização" e "letramento". Na prática, isso significa compreender primeiramente que muitos professores não possuem a ideia clara do que é "Alfabetização" e "Letramento" e quais são as especificidades de cada um desses termos.

O presente trabalho, então, terá como objetivo geral debater sobre as principais dificuldades enfrentadas pelos professores, em distinguir a "Alfabetização" e o "Letramento" nas séries iniciais, mais especificamente o ciclo de alfabetização que contempla as crianças matriculadas ente o 1 ㅇ e 3 을 anos do Ensino Fundamental.

Como objetivos específicos, esse estudo se propõe a: a) Entender do ponto de vista histórico como sugiram os conceitos de "Alfabetização" e "Letramento" e o que contribui para que tais conceitos pudessem, até os dias atuais, serem entendidos, de forma equivocada, como sinônimos na prática pedagógica de muitos professores; b) Conceituar à luz do referencial teórico os termos "Alfabetização" e "Letramento" destacando suas especificidades; c) Debater as principais ideias que os autores que estudam o tema explicam sobre a dificuldade em compreender o que "Alfabetização" e "Letramento"; d) Propor atividades práticas que auxiliem o professor no processo de alfabetização.

\section{METODOLOGIA}

Essa pesquisa está cadastrada na "Coordenadoria de Pesquisa, Desenvolvimento e Inovação" - CPDI da Unoeste, com o protocolo de número 3546 e já comtempla em seu texto as recomendações sugeridas pelo parecer dado. Caracteriza-se como qualitativa, de caráter bibliográfico, e usou de reflexão teórica crítica sobre o material obtido. Segundo Esteban (2010), a pesquisa qualitativa é a mais indicada para estudos educacionais, pois se utiliza de métodos que procuram compreender o processo e contexto em que a pesquisa ocorre.

Conforme Lakatos e Marconi (1992), a pesquisa bibliográfica permite compreender melhor o tema através de um estudo já em andamento, e auxilia na análise da solução do problema da pesquisa. "A pesquisa bibliográfica pode, portanto, ser considerada também como o primeiro passo de toda pesquisa científica" (LAKATOS; MARCONI, 1992, p. 44).

No caso dessa pesquisa, foram utilizados vários documentos para a coleta dos dados, como artigos científicos e pesquisas já concluídas nas bases de dados da "Coordenação de Aperfeiçoamento de Pessoal de Nível Superior" - CAPES, como Dissertações e Teses defendidas a partir de 2013, usando os descritores "Alfabetização" e "Letramento" como buscas principais. 
Portanto, o tratamento de informação realizado por esse estudo foi exclusivamente bibliográfico, cujo levantamento de dados ocorreu por meio de fontes bibliográficas e análises posteriores à luz do referencial teórico estudado, que virão, além da pesquisa na Plataforma Sucupira da CAPES, também de livros de autores renomados que estudam e pesquisam o tema, como Ferreiro e Teberoski (1999), Mortatti (2006), Soares (1989; 2003; 2004), entre outros.

Ao serem coletados os dados, houve um cruzamento das informações adquiridas durante a pesquisa com análise à luz dos referenciais já estudados e que discutem o tema. Segundo Lüdke e André $(1986$, p.48) é muito importante o estudo do referencial teórico a cerca de um assunto a ser estudado. É isso que promove o confronto entre a teoria existente com os dados coletados na pesquisa promovendo uma melhor análise dos fatos observados partindo para uma conclusão sobre o objeto desse estudo.

\section{RESULTADOS}

Pela história documentada percebe-se que a função da escrita não se limitava ao que hoje conhecemos como letras ou signos. Nossos antepassados foram registrando suas vivencias e se organizando para relatar a realidade que hoje nos permite chegar a evolução na escrita. Dada à existência desta organização de letras que permite chamar de escrita, buscamos seu histórico para compreendermos sua criação e sua influência para o desenvolvimento da humanidade.

Dentro do processo da evolução da escrita, de acordo com Ferreiro e Teberosky (1999), conseguimos observar três fases que são: Pictográfica: incapaz de representar sentimentos e ideias abstratas, representando somente com desenho os próprios objetos, necessitando de várias representações para passar seu conhecimento; Ideográfica: transforma signos anteriores, em ideias; Escrita Fonética: os signos passam a ter relação mais próxima com os sons.

A criança nasce num mundo letrado, onde olha e enxerga letras e símbolos que representam a comunicação para si e para seu mundo. Neste sentido, toda bagagem que a criança traz ao chegar à escola deve ser considerado e acrescentado à lapidação do professor agregando situações que oportunize a construção significativa de seu conhecimento.

Segundo Mortatti (2006), no final do século XIX o problema era a dificuldade das crianças aprenderem a ler e escrever. A partir da proclamação da República a educação passa a ser ideal de modernidade, onde a escola torna-se obrigatória, leiga e gratuita. Diante desse contexto a autora afirma que, é um novo mundo que instaura, onde haverá novos modos e conteúdos de pensar, sentir, querer e agir.

Nessa época utilizavam-se para o ensino da leitura o método sintético (que partia da "parte" para o "todo"); o da soletração (partindo do nome das letras); o fônico (partindo dos sons correspondentes às letras); e da silabação (emissão de sons), partindo das sílabas. Parafraseando Mortatti (2006), no ano de 1876 em Portugal o poeta português João de Deus publicou a Cartilha Maternal denominada também como Arte da Leitura.

Já na década de 1980, destacamos os estudos de Ferreiro (1986) que em conformidade com a prática construtivista também procura uma metodologia de trabalho e uma organização curricular previamente planejada, porque crianças e jovens em idade escolar não se deparam no mesmo ponto de partida e não aprendem da mesma maneira e do mesmo modo, mesmo que estejam em uma mesma turma ou série.

\section{DISCUSSÃO}

A alfabetização tem sido alvo de investigação nos dias atuais, pois já passou e ainda estamos passando por muitas mudanças em relações aos métodos, embasamentos teóricos e práticas pedagógicas. Todas essas mudanças fazem com que se busque uma reflexão sobre como ensinar os alunos por meio de uma visão critica sobre o que aprendem. 
No livro "Psicogênese da Língua Escrita" Ferreiro e Teberosky (1999) descrevem os níveis e as principais características das hipóteses sobre a linguagem escrita traçados pelas crianças. Todas as crianças passam por diversas etapas durante o seu processo de aquisição da língua escrita, criando hipóteses regulares que dependem do momento vivenciado por ela, evoluindo de uma etapa para outra quando a anterior for colocada em conflito.

É necessário que se entenda a escrita como uma representação simbólica da linguagem falada, e para que a criança aprenda realmente a ler e escrever ela precisa compreender não apenas o que a escrita representa, mas também de que forma ela representa, graficamente, a linguagem.

Além disso, na alfabetização, de acordo com o que é oportunizado para o aluno, este, inicialmente formula hipóteses sobre suas descobertas com relação à linguagem escrita e oral, e assim este pode ir ampliando seus conhecimentos, passando por fases, até o que se pode chamar da aquisição de sua alfabetização. Frente a isso, de acordo com Ferreiro e Teberosky (1999, p.284), a criança teria que ter a aquisição de cinco níveis de hipóteses de escrita para sua alfabetização.

Nível 1: hipótese pré-silábica: neste nível, se pode caracterizar sobre a presença de baixa diferenciação entre a escrita de uma palavra e outra, ou seja, seus traçados são quase sempre parecidos entre si. Muitas vezes, nem a própria criança identifica o que escreveu. Há uma mistura de desenhos e letras, mostrando que não existe a compreensão sobre a linguagem escrita.

Nível 2: intermediário I; neste nível, nota-se uma evolução sobre a utilização de caracteres. No entanto, ainda a há a utilização de diversos grafismos e sua escrita continua fora de compreensão.

Nível 3: hipótese silábica; ocorre o início das relações dentro do contexto oralidade e escrita e seu registro. Uma característica é o uso de uma letra para cada silaba que representa a fala, ou mais. No entanto, há o conflito na escrita do monossílabo, pois nesta fase julga ser necessário um número de letras para casa palavra.

Compreende-se então, que a criança que se enquadra como silábica busca a presença de características como a tentativa em apresentar um valor sonoro a cada letra do alfabeto, mostrando sua evolução, pois nos níveis anteriores não era estabelecido este vínculo.

Fica evidente que a alfabetização, a partir das concepções de Ferreiro e Teberosky (1999), acontece de modo sistematizado e contínuo, onde uma fase leva a outra, respeitando a aquisição de conhecimentos e ao mesmo tempo dando oportunidade para que a criança de valor e significados a sua aprendizagem.

A pesquisa que Ferreiro (1995) realizou sobre a Psicogênese da Língua Escrita implica em rever a mediação pedagógica do professor. Nesse sentido os métodos de alfabetização devem ser analisados com um olhar crítico, para que possam realmente se apresentar como um caminho para que o aluno se aproprie do sistema de representação alfabético e utilize a língua como prática social.

Moraes (2012), baseando-se também em Ferreiro e Teberoski (1999), explana sobre a compreensão acerca da estrutura do ato de alfabetizar, sendo que não se refere apenas como a aprendizagem de códigos e sim, apropriar de um sistema notacional. Diante disso, há a necessidade de compreender que:

Em primeiro lugar, precisamos reconhecer que, para o aprendiz da escrita alfabética, as "regras de funcionamento" ou propriedades do sistema não estão já "disponíveis", "dadas" ou "prontas" na sua mente. De início, ele não sabe como as letras funcionam, o tem uma visão ainda diferente da que nós, adultos alfabetizados, adotamos como se fosse à única possível. [...]

Em segundo lugar, a teoria da psicogênese da escrita mostra que, assim como a humanidade levou muito tempo para inventar o sistema alfabético, após ter usado outros sistemas de escrita (sistemas pictográficos, ideográficos, silábicos etc.), a internalização das regras e convenções do alfabeto não é algo que se dá da noite pro dia, nem pela mera 
acumulação de informações que a escola transmite, prontas, para o alfabetizando. (MORAIS, 2012, p. 48)

Ou seja, é preciso ter a consciência que a criança quando chega à escola traz consigo várias experiências, estas precisam ser aprimoradas dia a dia, e oportunizadas com atividades que de significado ao processo de construção de sua aquisição de conhecimentos.

\section{CONCLUSÃO}

A história da educação já passou por diversos métodos de alfabetização, que alegam ser o correto para se alfabetizar uma criança. Porém não existe o método certo e o errado, mas o uso adequado dele, de acordo com a necessidade da criança, pois um método que é de grande excelência para se alfabetizar uma criança, não é para a outra. Desta forma, deve-se fazer uso de diversos recursos para alfabetizar.

É preciso ter a consciência que a criança quando chega à escola traz consigo várias experiências, estas precisam ser aprimoradas dia a dia, e oportunizadas com atividades que de significado ao processo de construção de sua aquisição de conhecimentos. Então, o professor tem o papel de caminhar junto com a criança, considerando seus níveis, suas dificuldades para propor novas etapas de trabalho, novos desafios. Entendemos assim, que para a criança ser alfabetizada, necessita, antes de tudo, entender a natureza e as funções do nosso sistema de escrita, trabalhando ora seu letramento, ora sua alfabetização.

O que vemos tanto nos cursos de formação em pedagogia, como no próprio ambiente escolar são práticas pedagógicas que o professor busca tanto alfabetizar como letrar. Pode-se considerar que estamos passando por essa fase de desafios onde muito é cobrado do professor que saiba a questão da diferenciação da simples "alfabetização" dentro da perspectiva do alfabetizar letrando.

Desta forma, o letramento não é uma fragmentação da alfabetização e sim uma união, ou melhor, sua continuidade e ao mesmo tempo. O professor deve estar atento ao aluno, sua aprendizagem e o desenvolvimento de sua leitura e interpretação daquilo que ele mesmo lê e escreve.

\section{REFERÊNCIAS}

CARNEIRO, F. H. "Pacto Nacional para a Alfabetização na Idade Certa" - PNAIC: implicações sobre a prática pedagógica do professor no processo de alfabetização. 2016. $51 \mathrm{f}$. Trabalho de Conclusão de Curso (Licenciatura em Pedagogia) - Faculdade de Artes, Ciências, Letras e Educação de Presidente Prudente/SP - Universidade do Oeste Paulista - UNOESTE, Presidente Prudente, 2016.

ESTEBAN, M. P. S. Pesquisa qualitativa em Educação. Porto Alegre: Artmed, 2010, p 268.

FERREIRO, E. Alfabetização em processo. São Paulo: Cortez, 1986, 144 p.

FERREIRO, E. Reflexões sobre alfabetização. São Paulo: Cortez, 1995, 104 p.

FERREIRO, E.; TEBEROSKY, A. Psicogênese da escrita. Porto Alegre: Artmed, 1999, 300p.

LAKATOS, M. E. MARCONI, M. A. Metodologia do trabalho científico. São Paulo: Atlas, 1992, 317 p.

LÜDKE, M; ANDRÉ, M. E.D.A. Pesquisa em Educação: Abordagens Qualitativas. São Paulo, Editora Pedagógica e Universitária, 1986, 99 p.

MORAIS, A. G. Sistema de escrita alfabética. São Paulo, Melhoramentos, 2012. 
MORTATTI, M. R. L. História dos métodos de alfabetização no Brasil. Conferencia proferida no Seminário "Alfabetização e Letramento em debate". MEC, Brasília, 2006.

SANTOS, E. G. B.; COSTA, F. N. Alfabetização: questões históricas e atuais sobre os métodos. 2016. 35 f. Trabalho de Conclusão de Curso (Licenciatura em Pedagogia) - Faculdade de Artes, Ciências, Letras e Educação de Presidente Prudente/SP - Universidade do Oeste Paulista - UNOESTE, Presidente Prudente, 2016.

SOARES, M. Alfabetização: A (des)aprendizagem das funções da escrita. Educação em Revista, 8: 16-23, 1989

SOARES, M. A reinvenção da alfabetização. Presença Pedagógica, v.9, n.52, p. 15 - 21, Jul./ Ago. 2003.

SOARES, M. Letramento e alfabetização: as muitas facetas. Revista Brasileira de Educação, n.25, p. 5 - 17, Jan./ Fev./ Mar./ Mar./ p. 5 - 17, Jan./ Fev./ Mar./ Mar./ Abr. 2004. 